\author{
Innocenzo Sammarco \\ Gabriele Capurso \\ Luigi Coppola \\ Antonio Paniccià Bonifazi \\ Sara Cassetta \\ Gianfranco Delle Fave \\ Alessandro Carrara \\ Giovanni Battista Grassi \\ Pellegrino Rossi \\ Claudio Sette \\ Raffaele Geremia
}

\section{Expression of the proto-oncogene c-KIT in normal and tumor tissues from colorectal carcinoma patients}

Accepted: 17 February 2004

Published online: 6 May 2004

(C) Springer-Verlag 2004

\begin{abstract}
Background and aims: The proto-oncogene c-KIT encodes a tyrosine kinase receptor essential during embryonic development and postnatal life. Although deregulated expression of c-KIT has been reported, its role in colorectal carcinoma remains controversial: some authors have described a correlation between c-KIT expression and colorectal cancer (CRC), while others have failed to detect the receptor in the majority of neoplasia examined. To address this question, we designed a prospective study to analyze the expression of c-KIT in normal and neoplastic colonic mucosa of the same patient. Patients and methods: We analyzed the tissues of 20 patients undergoing surgical resection for colorectal carcinoma by reverse transcriptase-polymerase chain reaction, Western blot and immunohistochemistry, whose results were correlated with histopathological parameters. Results: Most patients (90\%) showed c-KIT expression in normal
\end{abstract}

tissue both at RNA and protein level, while in neoplastic tissue it was observed in $30 \%$ of patients at RNA level and in 10\% at protein level. By immunohistochemistry the localization of c-KIT protein in the normal colon was restricted to interstitial cells scattered in the stroma, whereas the non-neoplastic epithelium was always negative. The mucinous carcinomas were all c-KIT negative, whereas the only case in which c-KIT was displayed in the neoplastic epithelium was a G3 adenocarcinoma. Conclusion: Most colorectal carcinomas do not express c-KIT. We suggest that c-KIT expression is rarely present in this neoplasia; thus, the use of receptor inhibitors should be conducted in selected sub-groups of colon carcinoma patients, subsequent to the clear demonstration of cKIT overexpression in the neoplastic cells.

Keywords c-KIT · Colorectal cancer $\cdot$ Tyrosine kinases

\section{Introduction}

In spite of the major advances made toward its screening and early diagnosis, colorectal cancer (CRC) is one of the leading causes of cancer death in Western countries. For instance, in Europe CRC remains the second-mostfrequent neoplasia, with over 100 new cases per 100,000/ year and a 50\% 5-year survival rate [1]. However, the development of new chemotherapeutic agents is improving the survival, and the increased knowledge about the genetic and molecular basis of CRC now offers the opportunity for novel therapeutic approaches based on inhibition of specific targets with selected molecules or antibodies. Indeed, drugs that are able to inhibit the epidermal growth factor receptor (EGFR), or the vascular endothelial growth factor (VEGF), have shown activity against CRC and are being tested in clinical trials [2]. In this context, the evaluation of the expression and of the activity of different growth-related kinases in CRC might lead to new therapeutical approaches [3]. 
A potential therapeutic target in several human malignancies is the c-KIT receptor [4]. c-KIT is a type III tyrosine kinase receptor that plays a fundamental role in the establishment, survival, and maintenance of hematopoietic cells, melanocytes and germ cells [5]. Activation of c-KIT by its ligand stem cell factor (SCF) promotes dimerization and autophosphorylation of the receptor at specific tyrosine residues, which serve as docking sites for intracellular proteins involved in signal transduction pathways [5]. Aberrant expression of c-KIT and/or SCF has been reported in gastrointestinal stromal tumors (GISTs), breast, lung, neural and prostatic tumors [4]. c-KIT is required for differentiation or survival of some cancer cells and appears to positively correlate with carcinogenesis $[6,7]$. However, other authors have reported that KIT activation can instead promote apoptosis and be protective against development of other types of cancer [8,9].

With regard to CRC, while some authors have demonstrated the expression of both c-KIT transcript and protein [10], a number of other reports have shown rare if any expression of c-KIT in CRC tissue [11, 12, 13]. Most of these studies were retrospective and not specifically aimed at investigating c-KIT expression in CRC [11, 12], and did not analyze both the RNA and protein levels of cKIT in each patient.

The recent development and approval of the selective tyrosine kinase inhibitor [14] imatinib mesylate (STI571; Glivec, Novartis, Basel, Switzerland,) specific for c-KIT, $\mathrm{Abl}$ and PDGF receptor, as targeted therapy in chronic myelogenous leukemia (CML) [15] and GISTs [16],

Table 1 Demographical and clinicopathological parameters of the 20 patients evaluated. Each patient was classified according to pT stage and nodal status (pTNM system, UICC), histologic tumor type (adenocarcinoma or other type), tumor differentiation (G1 to 3 indicates high, medium, or low tumor cell differentiation, respec- makes the possible role of c-KIT in CRC of great interest.

We have therefore designed a prospective study to analyze matched normal and neoplastic tissues of CRC patients for c-KIT expression using Western blot, reverse transcriptase-polymerase chain reaction (RT-PCR), and immunohistochemistry. The results obtained are discussed in the frame of the current knowledge on the role of the c-KIT proto-oncogene in CRCs.

\section{Materials and methods}

Patients and tissues

CRC and corresponding normal samples were obtained, under informed consent, from 20 patients (mean age 66.5 years, twelve women, eight men) who underwent surgical resection at the Surgical Oncology Department of S. Filippo Neri Hospital, Rome, Italy. Clinical and demographical features of the population studied are detailed in Table 1. Each sample was divided in three parts, one of which was fixed in formalin for histological analysis; the remaining two were frozen in liquid nitrogen within 20-30 min of collection and stored at $-80^{\circ} \mathrm{C}$.

Gross and microscopic examination of the resected specimens included measurement of dimensions, an estimate of the depth of tumor invasion, and an assessment of the histological features (pTNM). Tumor samples free of necrosis were used for the following analyses.

\begin{tabular}{|c|c|c|c|c|c|c|c|c|c|}
\hline Case & Sex & Age & $\begin{array}{l}\text { Tumor } \\
\text { site }\end{array}$ & $\begin{array}{l}\text { Tumor } \\
\text { histology }\end{array}$ & $\begin{array}{l}\text { PTNM } \\
\text { stage }\end{array}$ & $\begin{array}{l}\text { Dukes' } \\
\text { class }\end{array}$ & $\begin{array}{l}\text { Tumor } \\
\text { diff. (G) }\end{array}$ & $\begin{array}{l}\text { CRC family } \\
\text { history }\end{array}$ & $\mathrm{Ki}-67$ \\
\hline 1 & $\mathrm{~F}$ & 60 & Left colon & Mucinous & T4N2M1 & $\mathrm{C}$ & 3 & No & + \\
\hline 2 & $\mathrm{~F}$ & 78 & Rectum & Adeno & $\mathrm{T} 2 \mathrm{~N} 1 \mathrm{Mx}$ & $\mathrm{C}$ & 3 & No & +++ \\
\hline 3 & $\mathrm{~F}$ & 52 & Left colon & Adeno & T4N1Mx & $\mathrm{C}$ & 3 & Yes & +++ \\
\hline 4 & $\mathrm{~F}$ & 74 & Left colon & Adeno & T3N1Mx & $\mathrm{C}$ & 3 & No & +++ \\
\hline 5 & M & 70 & Right colon & Mucinous & T3NOMx & $\mathrm{B}$ & 3 & No & +++ \\
\hline 6 & $\mathrm{~F}$ & 68 & Rectum & Adeno & T3NOMx & $\mathrm{B}$ & 3 & No & +++ \\
\hline 7 & M & 81 & Right colon & Adeno & T3NOMx & $\mathrm{B}$ & 3 & No & +++ \\
\hline 8 & $\mathrm{~F}$ & 75 & Rectum & Mucinous & T4N3M1 & $\mathrm{C}$ & 3 & No & +++ \\
\hline 9 & $\mathrm{M}$ & 67 & Rectum & Adeno & T3N0Mx & $\mathrm{B}$ & 3 & No & +++ \\
\hline 10 & M & 59 & Right colon & Adeno & $\mathrm{T} 4 \mathrm{~N} 3 \mathrm{Mx}$ & $\mathrm{C}$ & 3 & No & +++ \\
\hline 11 & $\mathrm{~F}$ & 60 & Rectum & Adeno & $\mathrm{T} 3 \mathrm{~N} 2 \mathrm{Mx}$ & $\mathrm{C}$ & 2 & No & +++ \\
\hline 12 & $\mathrm{~F}$ & 62 & Rectum & Cloacogenic & $\mathrm{T} 2 \mathrm{NxMx}$ & A & 3 & No & +++ \\
\hline 13 & $\mathrm{M}$ & 52 & Left colon & Mucinous & $\mathrm{T} 3 \mathrm{~N} 1 \mathrm{Mx}$ & $\mathrm{C}$ & 3 & No & +++ \\
\hline 14 & $\mathrm{~F}$ & 72 & Right colon & Adeno & T1NOMx & A & 2 & Yes & ++ \\
\hline 15 & $\mathrm{~F}$ & 39 & Left colon & Adeno & T2NOMx & A & 3 & No & +++ \\
\hline 16 & M & 80 & Left colon & Adeno & $\mathrm{T} 4 \mathrm{~N} 2 \mathrm{Mx}$ & $\mathrm{C}$ & 3 & No & +++ \\
\hline 17 & M & 77 & Right colon & Adeno & T3N0Mx & $\mathrm{B}$ & 3 & No & +++ \\
\hline 18 & $\mathrm{~F}$ & 49 & Right colon & Adeno & T3N0Mx & B & 2 & No & +++ \\
\hline 19 & $\mathrm{M}$ & 63 & Right colon & Adeno & T4N2M1 & $\mathrm{C}$ & 3 & ND & +++ \\
\hline 20 & $\mathrm{~F}$ & 86 & Left colon & Adeno & T3N0Mx & $\mathrm{B}$ & 2 & ND & +++ \\
\hline
\end{tabular}


Histological analysis

For histological analysis, paraffin-embedded formalin-fixed tissue samples of normal and neoplastic tissues were cut, and 3- $\mu \mathrm{m}$ thick sections were stained with hematoxylin-eosin stain. Each CRC was classified as adenocarcinoma, mucinous carcinoma and cloacogenic carcinoma according to the World Health Organization's histopatologic classification of digestive tract tumors. These were graded as moderately and poorly differentiated carcinomas.

\section{RNA and protein extraction}

Frozen normal and neoplastic tissues of every patient were used for RNA or protein extraction. Total RNA was extracted by homogenization of samples in TRIzol reagent (Invitrogen, Life Technologies Cat. No. 15596-026) following the manufacturer's instructions. Tissue fragments for protein extraction were homogenized in homogenization buffer (20 mM HEPES, pH 7.5, $120 \mathrm{mM} \mathrm{KCl}$, $0.1 \mathrm{mM}$ ethyleneglycol-bis ( $\beta$-aminoethyl ether)- $\mathrm{N}, \mathrm{N}, \mathrm{N}^{\prime}, \mathrm{N}^{\prime}$-tetraacetic acid, $1 \%$ Triton-X-100, $10 \mathrm{mM} \beta$-glycerophosphate, $10 \mu \mathrm{g} /$ $\mathrm{ml}$ leupeptin, and $10 \mu \mathrm{g} / \mathrm{ml}$ aprotinin). The extracts were centrifuged for $15 \mathrm{~min}$ at $12,000 \mathrm{xg}$ at $4^{\circ} \mathrm{C}$ before collecting the supernatant. The protein concentration in the supernatant was determined using the Bio-Rad protein assay (Bio-Rad, Cat. No. 5000006), following the manufacturer's instructions.

\section{RT-PCR analysis}

RT-PCR was performed using the RT-PCR kit (GibcoBRL, Life Technologies, Cat. No. 28025-021), according to the manufacturer's instructions. To synthesize complementary DNA (cDNA), $4 \mu \mathrm{g}$ total RNA and $750 \mathrm{ng}$ of random primers were used. For every cDNA the amplification reaction was made with primers for the $c$ kit gene and for the $\beta$-actin gene, used as internal control. The PCR was performed in $25 \mu \mathrm{l}$, using $1.5 \mathrm{mM} \mathrm{MgCl} 2,200 \mu \mathrm{M}$ of each $\mathrm{dNTP}$, and $1 \mu \mathrm{l}$ of cDNA reaction. For $c$-kit, the PCR protocol was as follows: $95^{\circ} \mathrm{C} / 5 \mathrm{~min}$ for denaturation step, followed by 35 cycles of denaturation at $95^{\circ} \mathrm{C}$ for $30 \mathrm{~s}$, annealing at $55^{\circ} \mathrm{C}$ for $30 \mathrm{~s}$, and extension at $72^{\circ} \mathrm{C}$ for $1 \mathrm{~min}$. The final extension period was $7 \mathrm{~min}$ at $72^{\circ} \mathrm{C}$. Two primers, spanning from exon 14 to exon 21 , were used: 5'-GGCCCACCCTGGTCATTACAGA-3' (forward) and 5'AGGGATCCTGCTCAGACATCGTCGTGCACAAG-3' (reverse). Primer concentration was $0.5 \mu \mathrm{M}$; the predicted size of the $c$-kitPCR product was 944 bp. For $\beta$-actin, the PCR protocol was as follows: $94^{\circ} \mathrm{C} / 5 \mathrm{~min}$ for denaturation step, followed by 30 cycles of denaturation at $94^{\circ} \mathrm{C}$ for $1 \mathrm{~min}$, annealing at $52^{\circ} \mathrm{C}$ for $1 \mathrm{~min}$, and extension at $72^{\circ} \mathrm{C}$ for $1 \mathrm{~min}$. The final extension period was $10 \mathrm{~min}$ at $72^{\circ} \mathrm{C}$. The primers used $(0.5 \mu \mathrm{M})$ were: $5^{\prime}$-CGTGGACATCCGCAAAGAC- $3^{\prime}$ (forward) and 5'-CTCGGCCACATTGTGAACT- $3^{\prime}$ (reverse). The predicted size of the $\beta$-actin-PCR product was 484 bp.

\section{Western blot analysis}

For detection of c-KIT protein, tissue extracts $(60 \mu \mathrm{g})$ were separated by SDS-PAGE, transferred onto polyvinylidene fluoride (PVDF) membrane (Immobilon-P, Millipore, Cat.No. IPVH00010), and subjected to Western blot analysis. Briefly, the first antibody incubation was carried out with either a polyclonal anti-c-KIT antibody (Santa Cruz Biotechnology, Inc., Cat. No. sc-168; 1:1000 dilution) or a rabbit polyclonal anti-Actin antibody (Sigma, Cat. No. A 2066; 1:500 dilution); secondary antibody incubation was carried out with antirabbit IgGs conjugated to horseradish peroxidase (Amersham, Cat. No. NA934; 1:10000 dilution). The anti-cKIT antibody is directed against aa. 958-976 within the carboxy terminal domain of the protein. The blot was developed using the ECL Western blotting chemiluminescence detection system (Santa Cruz Biotechnology, Inc., Cat. No. sc-2048), following the manufacturer's instructions. To compare the intensity of the bands between normal and neoplastic tissues, we used the Molecular Analyst software from Bio-Rad Laboratories, Inc. (version 1.4, Hercules, CA).

\section{Immunohistochemistry}

Sections from formalin-fixed and paraffin-embedded normal and tumor tissues were processed for immunohistochemistry using a policlonal anti-c-KIT antibody (Dako, Cat. No. A4502) or a monoclonal anti-Ki67 antibody (Dako, Cat. No. M72-10), both at 1:100 dilution. The sections were incubated with primary antibody for $1 \mathrm{~h}$, with biotinylated antibody for $20 \mathrm{~min}$, and with streptavidin for $10 \mathrm{~min}$. These latter two reagents were included in the "super sensitive immunodetection system kit" (Biogenex, Cat. No.QP900-9L) and were used following the manufacturer's instruction. The product of peroxidase reaction was revealed by $3-3^{\prime}$ diaminobenzidine tetrahydrochloride (DAB, UCS Diagnostic, Cat. No. DBC125). The slides were counterstained with hematoxilin and mounted with coverslips. Specific staining with anti-c-KIT antibody was defined as presence of staining in the plasma membrane and/or cytoplasm; specific staining with Ki67 was defined as presence of staining in the nuclei of tumor cells. Secondary antibody alone or non-immune rabbit IgGs used as controls did not produce staining. Tumors were assessed as c-KIT negative if all or most of the cancer cells were unstained $(<15-20 \%$ positive cells) and as c-KIT positive if $20 \%$ or more of the cells were immunostained. c-KIT positivity of stromal fibroblasts, infiltrating lymphocytes, mast cells, or Cajal cells was not considered.

The expression of Ki67 was evaluated on a three-point scale as follows: "+" if fewer than $20 \%$ of neoplastic cells were immunolabeled; "++" if $20 \%$ to $50 \%$ of neoplastic cells were immunolabeled and "+++" if more than $50 \%$ of neoplastic cells were immunolabeled. Positivity of samples for c-KIT and Ki67 was assessed by counting the positive cells in ten different fields.

\section{SAGE analysis}

The publicly available SAGEmap (http://www.ncbi.nlm.nih.gov/ SAGE) database was searched for expression of c-KIT (Hs.81665) in normal and neoplastic CRC cells. We searched two libraries of bulk normal colonic epithelium (B_NC1 and B_NC2), two bulk CRC tissues (B_Tu102 and B_Tu98) and four CRC cell lines (CL_HCT116, CL_Caco2, CL_SW837, CL_RKO).

\section{Results}

\section{Histology}

The histopathological features of the 20 patients are reported in Table 1 . In brief, the diagnosis of mucinous carcinoma was done in four cases, and of cloacogenic carcinoma in one case, the remaining 15 cases being adenocarcinomas. Sixteen out of the 20 cases were classified as grade 3, and the remaining four as grade 2. According to Dukes' class, ten cases were Dukes' C, seven Dukes' B and three Dukes' A. 
Table 2 Summary of the obtained results. For each patient, "+" means readily detected signal, "+/-" means low signal, and "-" means no detection. For the immunohistochemistry data, only signal in the epithelium of both normal $(N)$ and tumor $(T)$ samples is considered, while the positivity in the stroma is not reported because it was the same in all specimens of both normal and tumor samples. The asterisk means focal staining in less than $20 \%$ of the epithelial cells. The correlation column takes into account only the tumor samples; the label "Yes" means that the result obtained by immunohistochemistry correlates with that obtained by Western blot, or by both RTPCR and Western blot, in the same sample

\begin{tabular}{|c|c|c|c|c|c|c|c|}
\hline \multirow[t]{2}{*}{ Patient } & \multicolumn{2}{|c|}{$\begin{array}{l}\text { RT-PCR } \\
\text { (total tissue) }\end{array}$} & \multicolumn{2}{|c|}{$\begin{array}{l}\text { Western blot } \\
\text { (total tissue) }\end{array}$} & \multicolumn{2}{|c|}{$\begin{array}{l}\text { Immunohistochemistry } \\
\text { (epithelium only) }\end{array}$} & \multirow[t]{2}{*}{ Correlation } \\
\hline & $\mathrm{N}$ & $\mathrm{T}$ & $\mathrm{N}$ & $\mathrm{T}$ & $\mathrm{N}$ & $\mathrm{T}$ & \\
\hline 1 & + & - & + & - & - & - & Yes \\
\hline 2 & + & + & + & - & - & - & Yes \\
\hline 3 & + & - & + & - & - & + & No \\
\hline 4 & + & - & + & - & - & - & Yes \\
\hline 5 & + & $+/-$ & + & - & - & - & Yes \\
\hline 6 & + & $+/-$ & + & - & - & -* & Yes \\
\hline 7 & - & - & + & - & - & $-*$ & Yes \\
\hline 8 & + & - & + & - & - & - & Yes \\
\hline 9 & ND & ND & + & - & - & -* & Yes \\
\hline 10 & ND & ND & + & - & - & - & Yes \\
\hline 11 & + & $+/-$ & + & - & - & + & No \\
\hline 12 & ND & ND & + & - & - & - & Yes \\
\hline 13 & + & $+/-$ & + & - & - & - & Yes \\
\hline 14 & + & + & + & + & - & -* & No \\
\hline 15 & + & - & + & - & - & - & Yes \\
\hline 16 & + & $+/-$ & + & - & - & + & No \\
\hline 17 & + & + & + & ++ & - & ++ & Yes \\
\hline 18 & + & + & - & - & - & $-*$ & Yes \\
\hline 19 & - & - & - & - & - & -* & Yes \\
\hline 20 & + & + & + & - & - & + & No \\
\hline
\end{tabular}

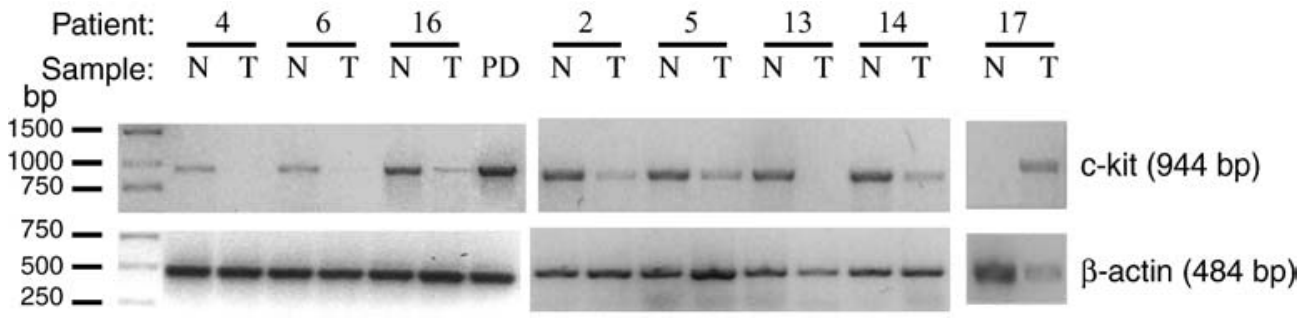

Fig. 1 C-KIT mRNA expression in colon carcinomas. c-KIT amplification from representative samples using oligonucleotide sequences corresponding to exon 14 (forward primer) and exon 21 (reverse primer). The expected band is $944 \mathrm{bp}$ long (upper panels). $\beta$-actin was amplified from the same samples as internal control of the RT-PCR, the expected band is 484 bp long (lower panels). For

\section{RT-PCR detection of c-KIT transcript}

RNA for PCR analysis was obtained from 17 of the 20 subjects examined. The cDNA obtained by RT reactions was amplified by PCR using a forward primer in the exon 14 and a reverse primer in the exon 21 . In the normal colon tissues we found that c-KIT was expressed in 15 samples $(88 \%)$, and not detected in two samples $(12 \%)$ (patients 7 and 19, Table 2). Interestingly, we found that among the 15 patients that showed c-KIT expression in the normal tissue, five did not express c-KIT mRNA in the tumor (33\%), five had a reduced expression level of the receptor $(33 \%)$ and five showed the same expression level as in the control counterpart (33\%) (Table 2). The two patients that were negative for c-KIT mRNA in the normal tissue were also negative in the neoplastic tissue (Table 2). c-DNA prepared from PD melanoma cell line, all patients $N$ means normal and $T$ means tumor tissue. $P D$ is a positive control obtained from a melanoma cell line. Marker is MBI Fermentas, Gene ruler $1 \mathrm{~Kb}$ (Cat.No. SM0311). Agarose gel (1\%). We ran $0.5 \mu \mathrm{g}$ for the marker, and half RT-PCR reaction for all samples

which expresses high levels of the c-KIT receptor, was used as positive control. The integrity of mRNA and efficiency of the RT reactions were assessed by amplifying the $\beta$-actin gene from the same samples. Representative samples are shown in Fig. 1. The upper panel shows the amplification of c-kit gene (944 bp band); the bottom panel shows the amplification of the $\beta$-actin gene (484 bp band) from the same samples.

Western blot analysis of c-KIT protein expression

We had the possibility to analyze all 20 patients by Western blot. In 16 patients $(80 \%)$ the c-KIT band showed a stronger intensity in normal than in neoplastic tissue (Table 2), and five representative samples are shown in Fig. 2. Two patients (10\%) showed either the 


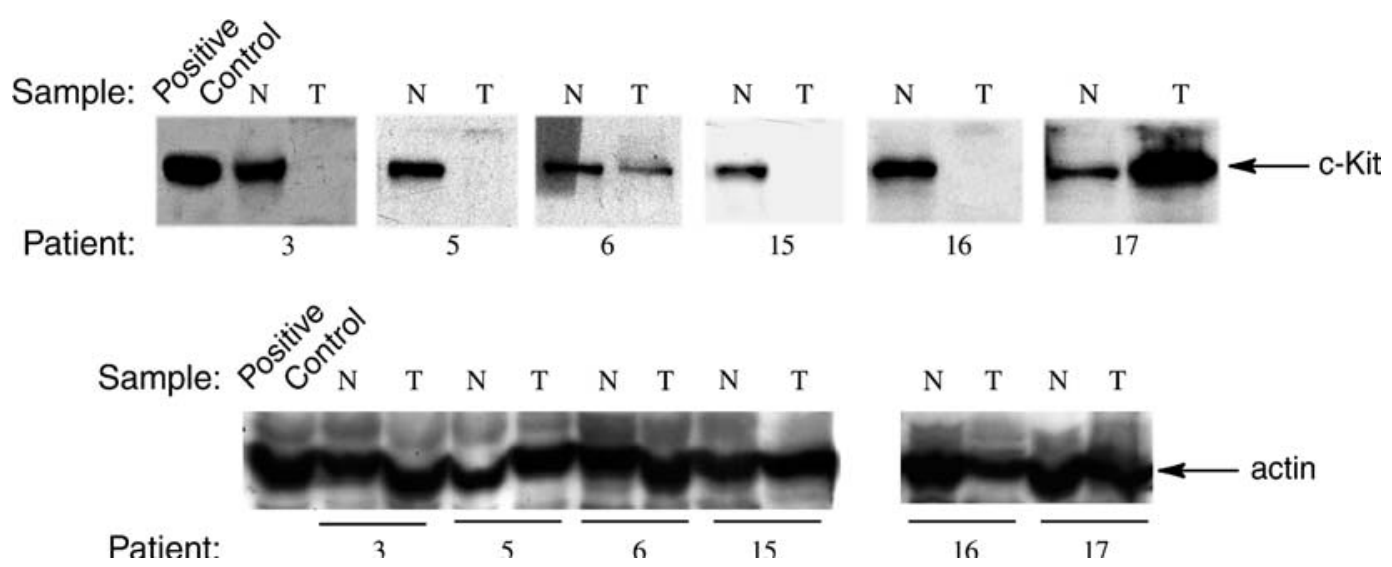

Fig. 2 C-KIT protein expression in colon carcinomas. Western blot analysis was performed using the anti-c-KIT antibody. Representative samples are shown. The band of $145 \mathrm{kDa}$ corresponding to cKIT is indicated. $N$ means normal and $T$ tumor tissues. The positive

control is recombinant c-KIT extracted from transfected cells. Staining with the anti-actin antibody, used as internal control of sample integrity, is shown in the lower panels: the expected band is $42 \mathrm{kDa}$; the positive control is a rat brain extract

same level of c-KIT expression in both normal and neoplastic specimens (patient 14, Table 2), or stronger expression in tumor than normal tissue (patient 17, Table 2). Finally patients 18 and 19 did not show detectable levels of expression of the c-KIT protein in either normal or neoplastic tissue (Table 2).

Comparing the patients that we could examine by both Western blot and RT-PCR, there was a good correlation in 13 out of 17 subjects $(76 \%)$ (Table 2). In three cases (patients 2, 18 and 20), we were able to detect c-KIT in the tumor by RT-PCR, but not by Western blot, while in only one case (patient 7) could we detect c-KIT in the control tissue by Western blot, but not by RT-PCR. Although we were able to amplify actin from this sample, it is possible that partial degradation of the mRNA had occurred. Thus, c-KIT expression appears to decrease in most cancer tissues examined both at the mRNA and at the protein levels.

In one patient in which c-KIT protein was decreased in the neoplastic tissue, we found that a truncated form of the receptor of approximately $27 \mathrm{kDa}$ was expressed both in non-neoplastic and tumor tissue (patient 20).

Detection of c-KIT protein by immunohistochemistry

To analyze the cellular localization of c-KIT protein, we performed immunohistochemistry on each specimen studied. Immunoreactivity to c-KIT was always absent in the epithelial compartment of samples from normal tissues (Table 2), while it was found to be localized in the stromal and inflammatory elements and it was not reported in Table 2. In the case of neoplastic tissues, nine out of the 16 patients in which c-KIT expression was decreased by Western blot analysis were completely negative at the epithelial level (Fig. 3A, B), three samples (patients 6, 7 and 9) showed a focal epithelial immunostaining ( $<20 \%$ of the cells; asterisks in Table 2$)$, and the last four samples (patients 3,11, 16 and 20), showed a more diffuse immunostaining at the epithelial level (between 20 and $50 \%$ of the epithelial cells). A focal epithelial immunostaining was also observed in two patients (patients 18 and 19) which did not express c-KIT both in normal and tumor tissue by Western blots and in one patient expressing-c-KIT at tumor level (patient 14) (Table 2). All neoplastic samples examined, due to expansion of the epithelial compartment, were characterized by a quite reduced stromal component. Since the stroma is the source of the only c-KIT positive cells in normal colon, its reduction in tumor samples may account for the decreased c-KIT protein and mRNA levels detected by our Western blot and RT-PCR analyses in tumor specimens with respect to normal tissue.

With regard to the patient (patient 17) in which cKIT was overexpressed in the tumor tissue, as judged by Western blot analysis, immunohistochemistry shows (Fig. 3D) that the epithelium of the neoplastic colon is strongly positive to c-KIT, whereas the normal epithelium (Fig. 3C) was negative, like in all the other patients examined.

Thus, c-KIT positivity in immunohistochemistry (from diffuse to strong staining) was found in five out of 20 patients examined $(25 \%)$. An interesting observation from the immunohistochemistry results is that c-KIT protein was never found in the epithelium of the four mucinous carcinomas and of the only cloacogenic carcinoma examined (compare Tables 1 and 2). In all tumor samples, we found a strong positive staining for the well-known marker of cell proliferation Ki-67 (Table 1); however, no relationship between $\mathrm{Ki}-67$ and c-KIT expression were found. 
Fig. 3A-D Immunolocalization of c-KIT in normal and neoplastic colon. Specimens from two patients are shown: in the upper panels are displayed the normal (A) and neoplastic (B) samples of patient 5, a representative example of patients in which c-KIT was decreased in the neoplastic tissue by both RT-PCR and Western blot. The c-KIT staining is restricted to stromal cells in both specimens; in the lower panels are displayed the normal $(\mathbf{C})$ and neoplastic (D) samples of patient 17 , in which c-KIT was overexpressed in the neoplastic tissue by both RT-PCR and Western blot. The c-KIT staining is restricted to mast cells and Cajal cells in the normal colon, whereas it is abundantly expressed in the epithelium of the neoplastic colon
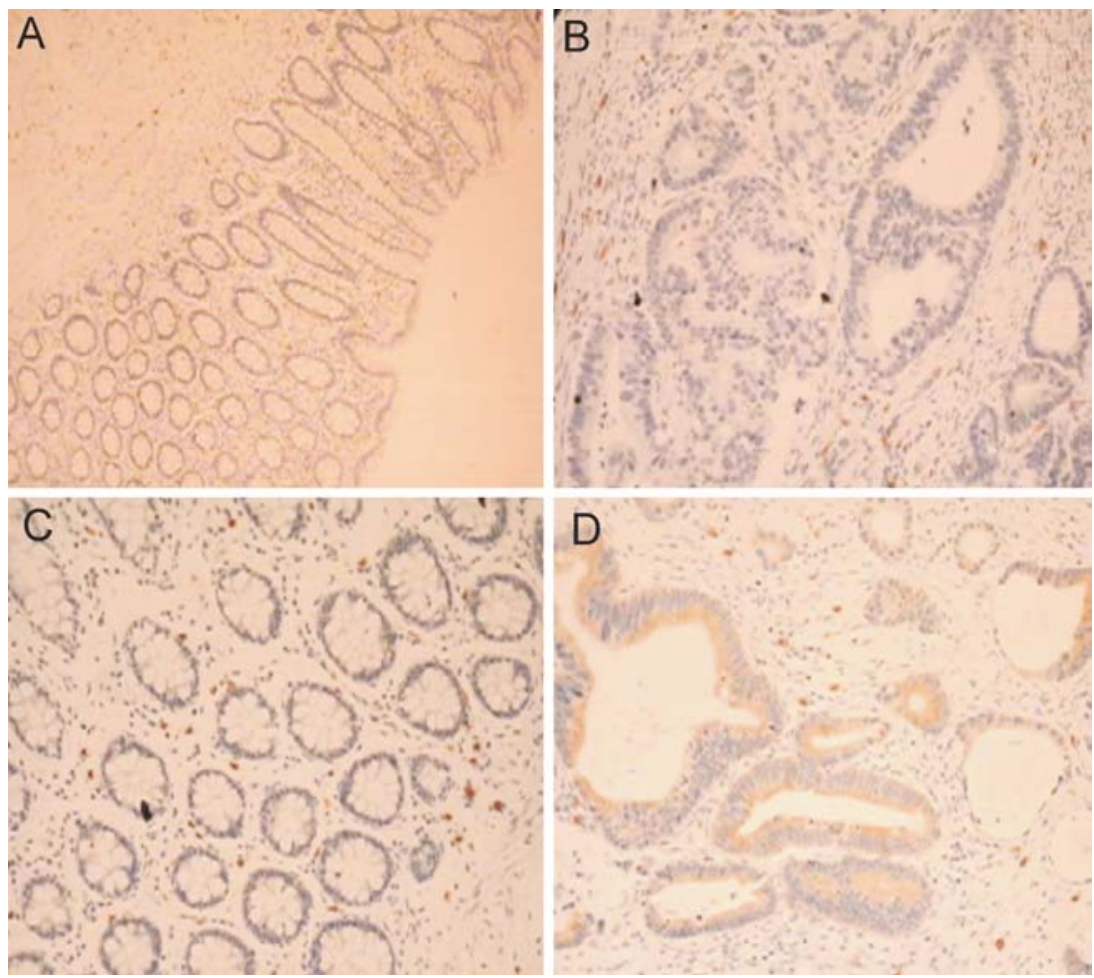

\section{SAGE analysis}

The available SAGEmap (http://www.ncbi.nlm.nih.gov/ SAGE) database was interrogated for the possible differential expression of c-KIT (Hs.81665) in normal and neoplastic CRC cells. We searched two libraries of bulk normal colonic epithelium (B_NC1 and B_NC2), two bulk CRC tissues (B_Tu102 and B_Tu98) and four CRC cell lines (CL_HCT116, CL_Caco2, CL_SW837, CL_RKO) but no tags corresponding to c-KIT were found in any of the libraries examined.

\section{Discussion}

Several studies have suggested the importance of c-KIT expression in a wide variety of human malignancies besides CML and GISTs, including germ cell tumors, smallcell lung carcinoma (SCLC), neuroblastoma, melanoma, ovarian carcinoma, breast carcinoma (reviewed in [4]) and, more recently, both exocrine [17] and endocrine [18] pancreatic tumors. However, in most of these cases the role of c-KIT in the neoplasia is not completely understood. Although it was reported that c-KIT kinase activity may help cell proliferation in some types of cancers [19, 20], in some other tumors such as breast cancer [21], thyroid tumors [22], and ovarian cancer [23], the malignant transformation and disease progression seem to associate with a loss of c-KIT protein expression. Moreover, activating mutations such as those found in GISTs have not been found in SCLC [24].

Similarly, reports offering a contrasting view on the role of c-KIT in CRC have been published: Bellone et al. showed that increased immunoreactivity to c-KIT is associated with neoplastic colonic tissues [10], whereas other groups have suggested that immunohistochemical staining for c-KIT is a rare event in human CRC $[11,12$, 13]. A possible reason for these conflicting results is that the authors did not correlate the expression of c-KIT in both the normal and neoplastic colon tissue for each patient examined.

In order to shed light on the importance of c-KIT expression in CRC, we attempted to examine c-KIT expression changes between normal and transformed colonic epithelium. To this end, we enrolled 20 subjects who underwent surgical resection and we investigated cKIT expression levels in both normal and neoplastic colon tissue of each patient by Western blot, RT-PCR, and immunohistochemistry.

We found that c-KIT expression was decreased in the progression from normal to cancer in $67 \%$ of the patients when examined by RT-PCR and in $80 \%$ of the patients when examined by Western blot analysis. Thus, in the majority of cases there is an agreement between results of Western blot analysis and RT-PCR. The discrepancy observed in the three cases in which c-KIT was detected by RT-PCR but not by Western blot (patients 2, 18 and 20, Table 2) might be due to a difference in sensitivity of 
the two techniques. A possible explanation for the lower signal that in most cases was observed in the neoplastic specimens of the patients both by Western blot and RTPCR is given by the results of immunihistochemistry study.

The immunohistochemical localization of c-KIT protein in the normal colon showed, as expected [11, 12, 25], a positive staining restricted to interstitial cells of Cajal, fibroblasts and mast cells scattered in the stroma, whereas the non-neoplastic epithelium was always negative. Similarly, in most neoplastic samples the transformed epithelium was negative. Due to the proliferation of the epithelial compartment, the stroma with the c-KIT-positive cells was reduced in neoplastic samples as compared with the matched normal samples. Thus, this reduction in the stroma content may account for the lower signal observed by Western blot and RT-PCR in most neoplastic specimens. Indeed, since we did not perform a systematic stripping procedure to isolate the mucosal layer, normal samples were more likely to include an intact submucosa, and possibly some cells from the muscular layers of the colonic wall, which are known to express c-KIT [25]. On the other hand, the neoplastic tissue was collected from exofitic lesions arising in the colon lumen, which had invaded and disrupted the submucosa. Therefore, the neoplastic samples were essentially composed by transformed epithelial cells.

As for the single patient that showed overexpression of c-KIT by Western blot in the tumor, we observed that the receptor was strongly expressed in the neoplastic epithelium. Thus, a positive correlation between c-KIT overexpression and neoplastic transformation occurs only in $5 \%$ of the patients in this study.

It is noteworthy to mention that we found five samples (patients 6, 7, 9, 18 and 19) with focal c-KIT reactivity in the neoplastic epithelium by immunohistochemistry (labeled with an asterisk in Table 2) which were not found to express c-KIT protein and/or mRNA by Western blot and RT-PCR. These data suggest that immunohistochemistry might give some non-specific results, as recently suggested [26], and should be integrated with other techniques for reliable evaluation of c-KIT expression, at least in CRC.

Interestingly, the very aggressive histological subtypes of cancer (patients 1, 5, 8, 12, and 13), herein classified as mucinous carcinomas and cloacogenic carcinoma, did not express c-KIT in the tumor cells. On the other hand, among the other aggressive carcinomas (G3 in Table 1) we found that only three samples displayed c-KIT reactivity in the epithelium, (patients 3,16 and 17); however, samples 3 and 16 did not express c-KIT protein or mRNA when examined by Western blot or RT-PCR analyses and only patient 17 was confirmed to overexpress the receptor in the neoplastic tissue at the molecular level. In a previous study in which a larger set of patients was analyzed (153 patients) it was shown that only two samples were positive to c-KIT by immunohistochemistry: these samples were classified as cloacogenic carcinomas T3N2Mx [13]. We examined only one cloacogenic carcinoma and it showed no expression of c-KIT by immunohistochemistry and Western blot. The heterogeneity of histotypes examined in our study and the limited number of samples for each histotype do not allow one to infer a clear correlation between c-KIT expression and the type of colon carcinoma under consideration. On the other hand, it is clear from our study and previous work [13] that expression of c-KIT in CRC is a rare event.

Interestingly, in one subject (patient 20) we noticed the presence of a truncated form of c-KIT of $27 \mathrm{kDa}$ in both normal and cancer tissues. This could be noteworthy because the presence of a c-KIT truncated form of the same size has already been observed in several colon cancer cell lines [27, 28]. Furthermore, our lab has cloned the mouse homologue of this alternative c-KIT product [29] and has shown that it is a strong activator of the Src-like kinases [30], a family of enzymes whose aberrant activation is associated with some human colon cancers [31, 32].

To date, a number of small molecules have been demonstrated to exert inhibition of tyrosine kinase activity in vivo and they are promising tools in the treatment of many human malignancies [33]. One of these compounds, STI571, selectively inhibits three tyrosine kinases: the soluble Abl, the PDGF receptor, and the c-KIT receptor, and it has been used with interesting results in the treatment of two very different cancers in which these protein kinases are aberrantly activated: CML and GISTs [15, 16]. Since most colorectal adenomas develop slowly before they become malignant, their gradual progression provides multiple opportunities to counteract tumor development. Recently, it has been proposed that STI571 might prove to be useful also for CRC therapy because STI571 inhibits cell proliferation and promotes apoptosis in HT29 cells [34]. However, although it was effective in vitro on a cell line, the study did not address the question of whether or not c-KIT activation occurs in primary CRCs.

Finally the finding that no tags for c-KIT were found in SAGE libraries of colon adenocarcinoma, suggesting that c-KIT expression is not a common event in this neoplasia, is in agreement with the results of our study showing that c-KIT expression is associated with a very small percentage of CRCs.

\section{Conclusion}

Our results indicate that while most normal colon samples express c-KIT as evaluated by RT-PCR ( $88 \%$ positive) and Western blot (90\% positive), the majority of colon tumor samples examined did not express the receptor at mRNA (70\% negative) or protein levels (90\% negative). 
However, as judged by immunohistochemistry, this decrease seems to be due to the reduction of stroma compartment, which contains c-KIT positive interstitial cells of Cajal, fibroblasts and mast cells, in neoplastic samples. We found that normal colon epithelium was always negative, whereas in $25 \%$ of the neoplastic samples the epithelium was reactive to c-KIT. However, in only one sample (5\% of the patients examined) this c-KIT immunoreactivity was confirmed by detection of c-KIT protein and mRNA with the other techniques. Thus, we suggest that c-KIT expression should be accurately evaluated with multiple techniques, when possible, to avoid the non- specific artifacts of immunohistochemistry observed in our study.

In conclusion, while an anti-c-KIT therapy may not be generally recommended for CRC, the use of c-KIT inhibitors together with conventional chemotherapy could be of some interest in clinical trials conducted in selected sub-groups of CRC patients, subsequent to the clear demonstration of c-KIT overexpression in the neoplastic cells.

Acknowledgements This work was supported by grants from CNR (CUO1) and MURST 2000.

\section{References}

1. Verdecchia A, Micheli A, Colonna M, Moreno V, Izarzugaza MI, Paci E (2002) EUROPREVAL Working Group. A comparative analysis of cancer prevalence in cancer registry areas of France, Italy and Spain. Ann Oncol 13:1128-1139

2. D'Entremont TS, Sun Weijing (2003) Recent advances in colorectal cancer therapy. Cancer Biol Ther 2:6-13

3. Traxler P (2003) Tyrosine kinases as targets in cancer therapy-successes and failures. Expert Opin Ther Targets 7:215-234

4. Heinrich MC, Blanke CD, Druker BJ, Corless CL (2002) Inhibition of KIT tyrosine kinase activity: a novel molecular approach to the treatment of KIT-positive malignancies. J Clin Oncol 20:1692-1703

5. Besmer P, Manova K, Duttlinger R, et al (1993) The kit-ligand (steel factor) and its receptor c-KIT/W: pleiotropic roles in gametogenesis and melanogenesis. Dev Suppl 125-137

6. Hassan HT, Zander A (1996) Stem cell factor as survival and growth factor in human normal and malignant hematopoiesis. Acta Haematol 95:257-262

7. Ricotti E, Fagioli F, Garelli, E, et al (1998) C-KIT is expressed in soft tissue sarcoma of neuroectodermic origin and its ligand prevents apoptosis of neoplastic cells. Blood 91:2397-2405

8. Huang S, Luca M, Gutman M, et al (1996) Enforced c-KIT expression renders highly metastatic human melanoma cells susceptible to stem cell factorinduced apoptosis and inhibits their tumorigenic and metastatic potential Oncogene 13:2339-2347

9. He J, deCastro CM, Vandenbark GR, Busciglio J, Gabuzda D (1997) Astrocyte apoptosis induced by HIV-1 transactivation of the c-kit protooncogene. Proc Natl Acad Sci USA 94:3954-3959
10. Bellone G, Silvestri S, Artusio E, et al (1997) Growth stimulation of colorectal carcinoma cells via the c-kit receptor is inhibited by TGF- $\beta 1$. J Cell Physiol 172:1-11

11. Natali PG, Nicotra MR, Sures I, Santoro E, Bigotti A, Ullrich A (1992) Expression of c-kit receptor in normal and transformed human nonlymphoid tissues. Cancer Res 52:6139-6143

12. Matsuda R, Takahashi T, Nakamura S, et al (1993) Expression of the c-kit protein in human solid tumours and in corresponding fetal and adult normal tissues. Am J Pathol 142:339-346

13. Reed J, Ouban A, Schickor FK, Muraca P, Yeatman T, Coppola D (2002) Immunohistochemical staining for c-kit (CD117) is a rare event in human colorectal carcinoma. Clin Colorectal Cancer 2:119-122

14. Manley PW, Cowan-Jacob SW, Buchdunger $E$, et al (2002) Imatinib a selective tyrosine kinase inhibitor. Eur J Cancer 38: S19-S27

15. Druker BJ, Sawyers CL, Kantarjian H, et al (2001) Activity of a specific inhibitor of the BCR-ABL tyrosine kinase in the blast crisis of chronic myeloid leukemia and acute lymphoblastic leukemia with the Philadelphia chromosome. N Engl J Med 344:1038-1042

16. Dagher R, Cohen M, Williams G, et al (2002) Approval summary: imatinib mesylate in the treatment of metastatic and/or unresectable malignant gastrointestinal stromal tumors. Clin Cancer Res 8:3034-3038

17. Esposito I, Kleeff J, Bischoff SC, et al (2002) The stem cell factor-c-kit system and mast cells in human pancreatic cancer. Lab Invest 82:1481-1492

18. Fjallskog ML, Lejonklou MH, Oberg KE, Eriksson BK, Janson ET (2003) Expression of molecular targets for tyrosine kinase receptor antagonists in malignant endocrine pancreatic tumors. Clin Cancer Res 9:1469-1473
19. Hibi K, Takahashi T, Sekido Y, et al (1991) Coexpression of the stem cell factor and the c-kit genes in small cell lung cancer. Oncogene 6:2291-2296

20. Timeus F, Crescenzio N, Valle P, et al (1997) Stem cell factor suppress apoptosis in neuroblastoma cell lines. Exp Hematol 25:1253-1260

21. Natali PG, Nicotra MR, Sures I, Mottolese M, Botti C, Ullrich A (1992) Breast cancer is associated with loss of the c-kit oncogene product. Int J Cancer 52:713-717

22. Natali PG, Berlingieri MT, Nicotra MR, et al (1995) Transformation of thyroid epithelium is associated with loss of ckit receptor. Cancer Res 55:1787-1791

23. Tonary AM, McDonald EA, Faugh W, Senterman MK, Vanderhyden BC (2000) Lack of expression of c-kit in ovarian cancers is associated with poor prognosis. Int J Cancer 89:242-250

24. Burger H, den Bakker MA, Stoter G, Verweij J, Nooter K (2003) Lack of c-kit exon 11 activating mutations in c-KIT/CD117-positive SCLC tumour specimens. Eur J Cancer 39:793-799

25. Lyford GL, He C-L, Soffer E, et al, (2002) Pan-colonic decrease in interstitial cells of Cajal in patients with slow transit constipation. Gut 51:496501

26. Hornick JL, Fletcher CD, (2003) Validating immunohistochemical staining for KIT (CD117). Am J Clin Pathol 119:325-327

27. Toyota M, Hinoda Y, Itoh F, Takaoka A, Imai K, Yachi A (1994) Complementary DNA cloning of truncated form of c-kit in human colon carcinoma cells. Cancer Res 54: 272-275

28. Takaoka A, Toyota M, Hinoda Y, Itoh F, Mita H, Kakiuchi H, Adachi M, Imai K (1997) Expression and identification of aberrant c-kit transcripts in human cancer cells. Cancer Lett 115:257-261 
29. Rossi P, Marziali G, Albanesi C, Charlesworth A, Geremia R, Sorrentino V (1992) A novel c-kit transcript, potentially encoding a truncated receptor, originates within a kit gene intron in mouse spermatids. Dev Biol 152:203207

30. Sette C, Paronetto MP, Barchi M, Bevilacqua A, Geremia R, Rossi P (2002) Tr-kit-induced resumption of the cell cycle in mouse eggs requires activation of a Src-like kinase. EMBO J 21:5386-5395
31. Irby RB, Mao W, Coppola D, Kang J, Loubeau JM, Trudeau W, Karl R, Fujita DJ, Jove R, Yeatman TJ (1999) Activating SRC mutation in a subset of advanced human colon cancers. Nat Genet 21:187-190

32. Windham TC, Parikh NU, Siwak DR, Summy JM, McConkey DJ, Kraker AJ, Gallick GE (2002) Src activation regulates anoikis in human colon tumor cell lines. Oncogene 21:7797-7807
33. Shawer L, Slamon D, Ullrich A (2002) Smart drugs: tyrosine kinase inhibitors in cancer therapy. Cancer Cell 1:117123

34. Attoub S, Rivat C, Rodrigues S, et al (2002) The c-kit tyrosine kinase inhibitor STI571 for colorectal cancer therapy. Cancer Res 62:4879-4883 